\title{
Pharmacokinetics of imidazole antimycotics
}

\author{
M. Plempel \\ M.D. \\ Institute of Chemotherapy, Bayer Research-Center, D-5600 Wuppertal-1/West Germany
}

\begin{abstract}
Summary
According to data on the imidazole antimycotics at present on the market, none of these products satisfactorily fills the gaps which exist in the treatment for mycoses of internal organs, although they have brought considerable progress in the topical treatment of mycoses.

On the basis of their very broad spectrum and high intensity of activity under suitable test conditions, and the comparatively tolerable amount of side effects in man, the present imidazole antimycotics are considered to be an encouraging start for future development of derivatives which will lead to products with considerably better pharmacokinetic, and therefore better therapeutic, properties.
\end{abstract}

\section{Introduction}

At present there are 3 imidazole antimycotics on the market - clotrimazole, miconazole and econazole (Fig. 1).

It is known that for the antimycotic activity of these agents, both the unsubstituted imidazole ring and the $\mathrm{N}-\mathrm{C}$ linkage between the imidazole ring and the rest of the molecule are essential (Fig. 2).

Substitutions in the $x, y$ and $z$ positions can vary widely and alter the pharmacokinetic properties of the substances more than the antimycotic properties. The study of the antimycotic activity of imidazole antimycotics is complicated both in vitro and in vivo. Separate consideration will be given to the kinetics of activity of imidazoles on fungi - the microbiological pharmacokinetics, and the pharmacokinetics and bioavailability in laboratory animals and man (Bennett et al., 1978).

\section{Kinetics of imidazole activity on micro-organisms}

In addition to the broad spectrum of activity in vitro the antimycotic action of the imidazoles as characterized firstly by a lag phase of several hours between administration of the active substance and the onset of antimycotic action and secondly by an indistinct minimal inhibitory concentration (MIC) which depends upon the site of the inoculum, the incubation time, the nutrient medium used, and the physiological condition of the organisms tested (proliferative or sporing stage). The third charac-
Clotrimazole (Bayer) 1967 Canesten

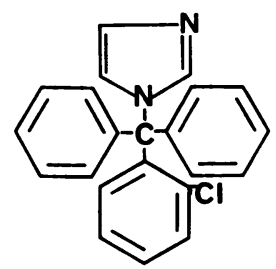

Miconazole (Cilag/Janssen) 1968

Epi/Gyno-Monistat

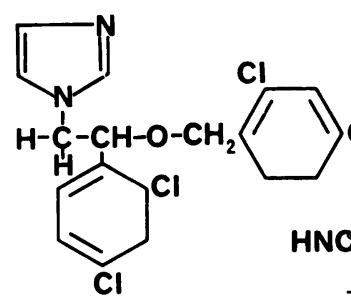

Econazole (Cilag/Janssen) 1968

Pevaryl

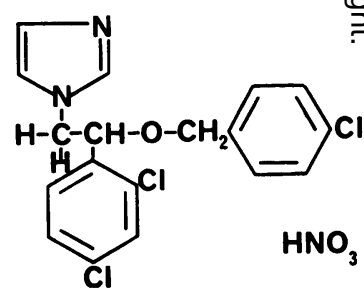

Fig. 1. Chemical structures of commercially available imidazole antimycotics.<smiles>[X]C([X])([X])n1ccnc1</smiles>

FIG. 2. General formula of azole antimycotics.

teristic of imidazole pharmacokinetics is their $\mathfrak{\omega}_{\mathrm{W}}$ primary fungistatic type of activity which changes into an increasing, secondary fungicidal action only 0 at concentrations of $10-20 \mathrm{mg} / \mathrm{l}$ and reaction times of $>96 \mathrm{hr}$. The fungicidal potency varies with $\stackrel{?}{+}$ 
different derivatives (Haller and Plempel, 1978; Plempel, 1978). In international literature there have been many different interpretations particularly regarding the phenomena 'inoculum effect' and 'effect of incubation time'. The MICs of clotrimazole and miconazole against an inoculum of $10^{3} / \mathrm{ml}$ Candida albicans cells in yeast nitrogen medium are $1-2 \mathrm{mg} / \mathrm{l}$. If the inoculum size is $10^{7} \mathrm{cells} / \mathrm{ml}$ the MICs are 32 and $64 \mathrm{mg} / 1$ respectively. Econazole shows a similar inoculum dependence (Haller and Plempel, 1978).

The usual explanation for such a reaction, derived from experience gained in antibacterial chemotherapy, assumes the presence of individual mutant and resistant organisms in a certain inoculum size. The inoculum effect would then be a result of the selection of these mutants by the active substance which would in effect produce a subpopulation resistant to the active substance.

The observation that inocula of $\leqslant 10^{4} \mathrm{cells} / \mathrm{ml}$ are normally sensitive to imidazole may only indicate a mutation frequency of $10^{5}$ or less.

\section{Effect of incubation time}

In agar diffusion and agar dilution tests a slow regrowth of initially inhibited colonies is noted when the incubation time is prolonged. After incubation for about 150-190 hr, these achieve the growth density of control colonies which were fully grown after only $48 \mathrm{hr}$. This effect is also usually explained as the result of a selection of variants resistant to the active substance. This is contradicted by the fact that isolates from such subsequently grown organisms have normal MIC values against imidazoles when a normal, non-prolonged incubation period is used (Plempel, 1978).

If the kinetics and mechanism of action of the imidazoles are examined there are other interpretations for both phenomena which correspond to the clinical efficacy and therefore may be more accurate.

When clotrimazole is added to a suspension of yeasts there is an initial lag phase of 3 to $4 \mathrm{hr}$ followed by a reduction in cell division. Amphotericin $B$, in contrast, forms complexes with ergosterol in the cell membranes followed by a cessation of cell division and some cell lysis. A fundamental aspect of imidazole kinetics in fungi is the retardation - not inhibition - of multiplication of organisms after the end of the lag phase. This is deducible from the mode of action of clotrimazole in yeasts (Fig. 3).

Before clotrimazole can become active the ergosterol pool stored in the organisms' cytoplasm must be exhausted. This determines the lag phase.

Inhibition of enzymatic conversion of lanosterol to ergosterol is obviously not complete for clotrimazole and probably not for miconazole and econazole (similar to the inhibition of the formation of

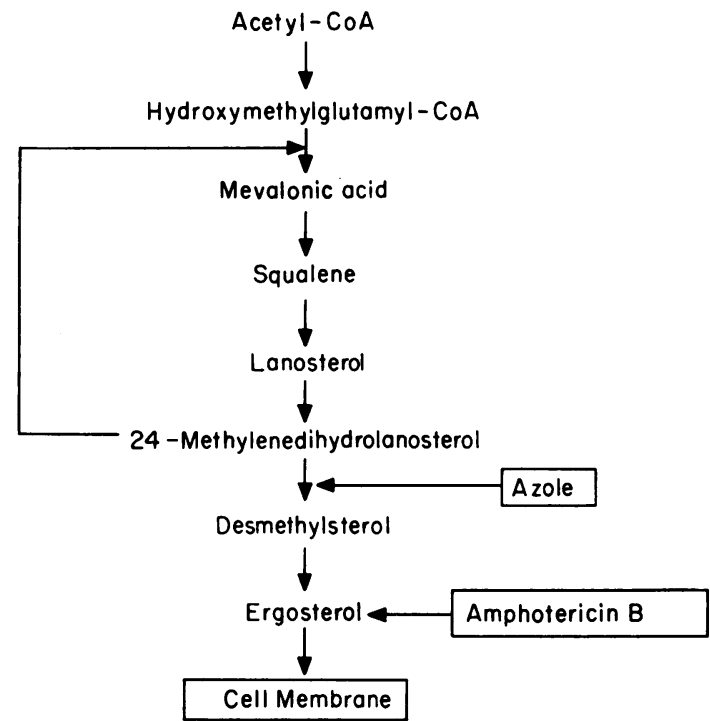

Fig. 3. Suggested mode of action of clotrimazole in yeasts.

tetrahydrofolic acid from para-aminobenzoic acid by sulphonamides in the case of bacteria) and in low concentrations clotrimazole produces only a slowing down of the multiplication processes.

If both these effects are correlated, inoculum effect and effect of incubation time appear to be only visual impressions gained from the interpretation of turbidity in the serial dilution test or colony sizes in the agar dilution test.

An inoculum of $10^{4}$ organisms $/ \mathrm{ml}$ produces approximately $5 \times 10^{6}$ organisms $/ \mathrm{ml}$ in $48 \mathrm{hr}$ in the absence of any drug. These are easily visible on reading the result as turbidity or colony formation. In the presence of imidazole $1-5 \times 10^{5}$ organisms $/ \mathrm{ml}$ are produced which are not, or only just, visible as turbidity or colony formation after $48 \mathrm{hr}$, but which become increasingly more visible with longer incubation and slower continued multiplication of the organisms. An inoculum of $10^{6}$ organisms $/ \mathrm{ml}$ produces viable counts of $10^{7}$ organisms $/ \mathrm{ml}$ after incubation for $48 \mathrm{hr}$ (>10 $0^{8}$ for the controls) which are visible with either method and give the impression of normal microbial growth although the actual viable count is $\leqslant 10 \%$ of the untreated controls.

The effect of inoculum and incubation time on imidazoles is therefore dependent upon the mechanism of action and methods used for reading the test results and is not caused by the selection of mutant, non-sensitive variants.

The limited activity on proliferating organisms is also a consequence of the mechanism of action of imidazoles: only actively growing organisms use 
sterols for membrane synthesis. Active metabolism is therefore essential for imidazole activity, in contrast to amphotericin $B$ which acts on preformed membrane components.

The primary fungistatic effect of current imidazoles is a result of partial inhibition of de novo synthesis of sterols - killing can only take place in rapidly proliferating organisms by extensive membrane defects and the loss of essential plasma components or with high concentrations of active substance as a result of secondary effects. Primary fungicidal activity can be observed in new imidazole derivatives with high affinity for the steroidsynthetizing enzymes (Plempel, 1978).

The essential background to the substrate dependence of imidazole activity on fungi, which must be interpreted as nutrient medium antagonism, is still not clear. Lipids, mevalonic acid and organic acids from the tricarboxylic acid cycle and also certain amino acids, e.g. histidine, are regarded as antagonists.

The substrate dependence of the in vitro activity of imidazoles against fungi and its interpretation show how critically results on in vitro sensitivity testing for this group of active substances must be assessed. Even though the clinical efficacy of this group of active substances has been clearly substantiated, findings are still overlooked or disregarded which are readily accepted in the case of flucytosine, a substance equally activity-dependent in some in vitro parameters.

\section{Pharmacokinetics of imidazoles in macro-organisms Animal experimental data}

Early investigations with clotrimazole given orally to mice, guinea-pigs and rabbits showed good intestinal absorption of the active substance and satisfactory serum levels which correlated with the effects of treated animals infected with C. albicans (Fig 4).

The enzyme-inducing power of clotrimazole was subsequently discovered in mice. With increasing numbers of oral administrations this phenomenon was manifested as an increasingly rapid metabolism of the active substance and a consequent reduction in the serum levels with the same dosage (Fig. 5). It was also demonstrated in the hexobarbitone-sleep test (Otten and Plempel, 1975; Plempel, 1978).

Miconazole and econazole, given orally, are comparable with clotrimazole in mice with regard to their enzyme-inducing power and their metabolism by induced liver enzymes. This specific, very rapid, enzyme induction in mice is the reason for failure of treatment with imidazoles given orally in experimental mycoses of long duration with prolonged administration of the agents.

Less than $1 \%$ of the dose is excreted in the urine

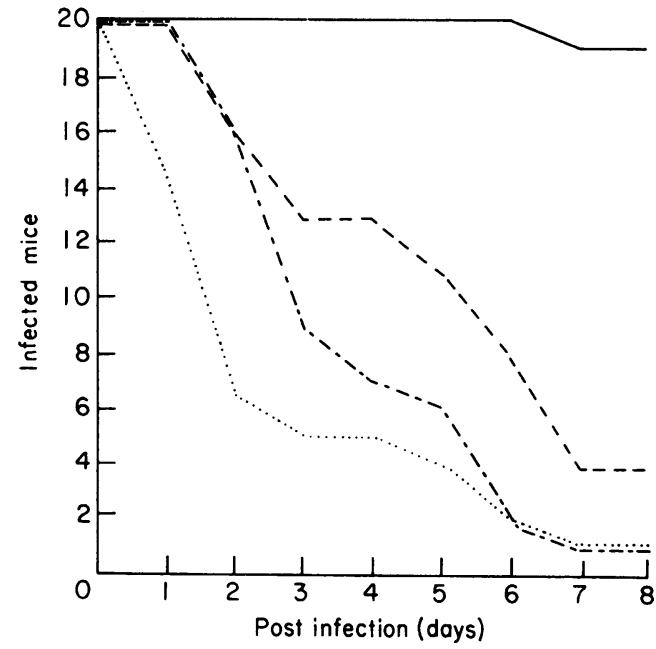

FIG. 4. Experimental candidiasis in mice. Survival rates after oral application of $100 \mathrm{mg} / \mathrm{kg}$ body weight once daily. __ Clotrimazole; _- _- econazole; -..-miconazole; $\cdots \cdot$ untreated controls.

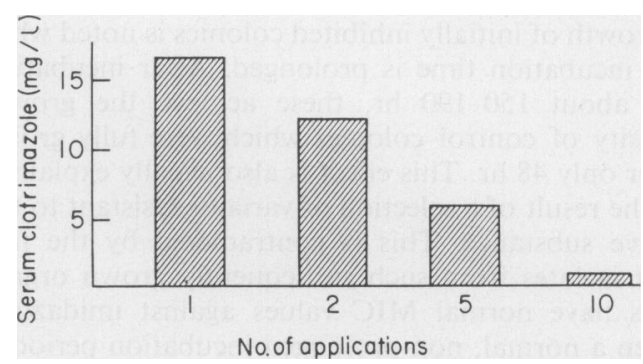

FIG. 5. Serum levels of clotrimazole in mice $2 \mathrm{hr}$ after repeated application of $100 \mathrm{mg} / \mathrm{kg}$ body weight showing the effect of enzyme induction.

in a microbiologically active form for all 3 imidazoles (Plempel, 1978).

The viable count of $C$. albicans - cells $/ \mathrm{ml}$ of renal homogenate from infected and non-treated mice, compared with that from mice treated with imidazoles, was taken as a measure of imidazole activity in tissue. It is considered that with this test the efficacy of antimycotic treatment with imidazoles can be better evaluated than simply by noting the survival rates in infected and treated animals, particularly if determination of viable counts in the renal homogenates is dose-related. The antimycotic potency of the imidazoles is demonstrated by the fact that despite marked enzyme induction in mice it is possible to reduce the organisms in the tissue in comparison with non-treated controls (Fig. 6).

Elimination of imidazoles in the faeces of orally treated animals progresses, after $80 \%$ intestinal 


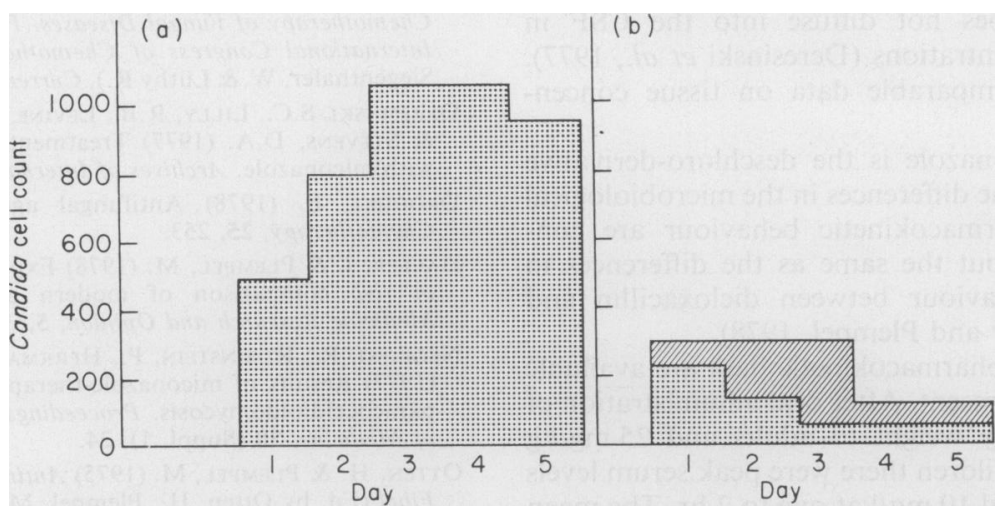

FIG. 6. Candida cell counts in mouse kidney homogenates. (a) Untreated controls. (b) Chemotherapy: $\mathscr{G}$ miconazole $2 \times 100 \mathrm{mg} / \mathrm{kg}$ body weight per day: $2 \times 100 \mathrm{mg} / \mathrm{kg}$ body weight per day.

absorption, in mostly metabolized form via the bile. In rats, for example, enterohepatic circulation of active substance and metabolites occurs.

The pharmacokinetics of imidazoles in animals is species related. There are large differences in blood levels, rate of enzyme induction, amount of absorption and tissue diffusion for the individual substances between rats, rabbits, dogs and monkeys. This is also shown in the toxicology data for the different substances in these species of animals.

\section{Human pharmokinetic data}

The following data emerge for the pharmacokinetics of clotrimazole, miconazole and econazole in man (Otten and Plempel, 1975; Seo, 1977; Drouhet, 1978; Plempel, 1978):

Clotrimazole. After oral administration of $20 \mathrm{mg} /$ $\mathrm{kg}$ body weight, the peak serum levels are 0.5-1.5 $\mathrm{mg} / \mathrm{l}$, with wide individual and intra-individual fluctuations; the serum half-life is between 4.5 and $6 \mathrm{hr}$. A particular problem after oral administration of clotrimazole is the rapid occurrence of enzyme induction effects, which vary individually. There are slow inactivators for clotrimazole (as there are for isonicotinic acid hydrazide) where after 3 weeks' treatment only a slight reduction or no reduction at all in serum concentration is measurable, owing to increasingly rapid metabolism and inactivation by enzymes. There are also rapid inactivators, so that after about one week's oral treatment, only traces of microbiologically active substance are still evident in the serum, in addition to large quantities of inactive metabolites. Because of enzyme induction, oral administration of clotrimazole in systemic mycoses is not recommended.

Clotrimazole is also eliminated from man in a microbiologically inactive form via the kidneys and faeces. Diffusion into CSF even when the meninges are inflamed is therapeutically inadequate (Otten and Plempel, 1975).

A few studies have shown tissue levels of active clotrimazole in muscle and fatty tissue in the range 0.5-1 mg/kg (Otten and Plempel, 1975; Plempel, 1978).

In spite of these problematic, pharmacokinetic properties, clotrimazole has been shown to be therapeutically effective in about 550 cases of confirmed or suspected systemic mycoses caused by Candida spp. and Aspergillus spp. (Weuta, 1974).

The use of clotrimazole nowadays is mainly restricted to the local treatment of mycoses, e.g. of the skin and mucous membranes. In such cases, results of treatment are very good.

Miconazole. Miconazole administered orally to man produces low serum levels with wide individual differences. Nothing is known of enzyme-induced metabolism for miconazole after oral administration. Metabolism occurs during the first passage through the liver following intestinal absorption via the portal circulation after oral administration. When given i.v. with individual doses of $10-12 \mathrm{mg} / \mathrm{kg}$ body weight, short-term peak serum levels of between 5 and $13 \mathrm{mg} / \mathrm{l}$ are produced which, after approximately $30 \mathrm{~min}$, fall to $2-5 \mathrm{mg} / \mathrm{l}$; and after approximately $12 \mathrm{hr}$, to $0.5 \mathrm{mg} / \mathrm{l}$. Miconazole is $95 \%$ protein bound (Stevens, 1976; Drouhet, 1978). Like clotrimazole, miconazole administered orally or i.v. is renally eliminated in unchanged form in only minimal amounts. Approximately $10 \%$ of the dose is excreted unchanged in the faeces. Even after prolonged i.v. administration of miconazole to man there are no enzyme induction effects. This is in contrast to the effects in mice.

Organisms with an in vitro MIC of $1.25 \mathrm{mg} / 1$ can be regarded as sensitive in vivo (Stevens, 1976; Negroni et al., 1977). 
Miconazole does not diffuse into the CSF in therapeutic concentrations (Deresinski et al., 1977). There are no comparable data on tissue concentrations.

Econazole. Econazole is the deschloro-derivative of miconazole. The differences in the microbiological activity and pharmacokinetic behaviour are considered to be about the same as the differences in activity and behaviour between dicloxacillin and cloxacillin (Haller and Plempel, 1978).

Only minimal pharmacokinetic data are available on econazole at present. After oral administration of $13-20 \mathrm{mg} / \mathrm{kg}$ body weight to adults and $25 \mathrm{mg} / \mathrm{kg}$ body weight to children there were peak serum levels of between 0.2 and $10 \mathrm{mg} / \mathrm{l}$ at one to $2 \mathrm{hr}$. The mean values one to $3 \mathrm{hr}$ after administration were between 0.6 and $1.5 \mathrm{mg} / \mathrm{l}$ and therefore largely correspond to those found for clotrimazole in oral doses of 20 $\mathrm{mg} / \mathrm{kg}$ body weight (Drouhet, 1978).

Econazole does not appear to be metabolized in the liver to the same extent as clotrimazole, and in the few cases described to date (1978) showed no increasingly rapid degradation as a result of enzyme induction.

\section{References}

Bennett, J., Plempel, M., Stevens, D. \& Scholer H. (1978) Amphotericin B used in combination with other drugs. In:
Chemotherapy of Fungal Diseases. Proceedings of the 10th International Congress of Chemotherapy (1977). (Ed. by Siegenthaler, W.\& Lüthy R.). Current Chemotherapy, 1, 53.

Deresinski, S.C., Lilly, R.B., Levine, H.B., Galgiani, J.N. \& Stevens, D.A. (1977) Treatment of fungal meningitis with miconazole. Archives of Internal Medicine, 137, 1180.

Drounet, E. (1978) Antifungal agents. Antibiotics and Chemotherapy, 25, 253.

Haller, I. \& Plempel, M. (1978) Experimental in vitro and in vivo comparison of modern antimycotics. Current Medicine Research and Opinion, 5, 315.

Negroni, R., Rubinstein, P., Herrman, A. \& Gimenez, A. (1977) Results of miconazole-therapy in 2 8patients with paracoccidioidomycosis. Proceedings of the Royal Society of Medicine, 70 (Suppl. 1), 24.

Otten, H. \& Plempel, M. (1975) Antimykotika. AntibiotikaFibel (Ed. by Otten, H., Plempel, M. \& Siegenthaler, W.) p. 666. G. Thieme-Verlag, Stuttgart.

Plempel, M (1978) Die Imidazol-Antimykotika Erkennung und Behandlung systemischer Mykosen, p.55. Editiones Roche/Basel.

SEO, M. (1977) Basic experiments with clotrimazole administered orally. Current Medicine Research and Opinion, 5, 169.

Stevens, D.A. (1976) Miconazole in coccidioidomycosis. American Journal of Medicine, 10, 191.

SUNG, J.P. (1977) Intravenous and intrathecal miconazoletherapy for systemic mycoses. Western Journal of Medicine 126, 5.

WeUtA, H. (1974) Clinical studies with oral clotrimazole Postgraduate Medical Journal, 50, (Suppl. 1), 45. 